\title{
Engineered Nanoparticles Mimicking Cell Membranes for Toxin Neutralization
}

\author{
Ronnie H. Fang, Brian T. Luk, Che-Ming J. Hu*, Liangfang Zhang*
}

\begin{abstract}
Department of NanoEngineering and Moores Cancer Center, University of California, San Diego, La Jolla, CA 92093, USA
\end{abstract}

*Address correspondence to $\underline{\mathrm{c} 4 h \mathrm{~h} @ \text { ucsd.edu and zhang@ucsd.edu }}$

\begin{abstract}
Protein toxins secreted from pathogenic bacteria and venomous animals rely on multiple mechanisms to overcome the cell membrane barrier to inflict their virulence effect. A promising therapeutic concept toward developing a broadly applicable anti-toxin platform is to administer cell membrane mimics as decoys to sequester these virulence factors. As such, lipid membranebased nanoparticulates are an ideal candidate given their structural similarity to cellular membranes. This article reviews the virulence mechanisms employed by toxins at the cell membrane interface and highlights the application of cell-membrane mimicking nanoparticles as toxin decoys for systemic detoxification. In addition, the implication of particle/toxin nanocomplexes in the development of toxoid vaccines is discussed.
\end{abstract}

Keywords: detoxification, virulence factors, anti-toxin nanoparticles, liposomes, cell membranes, nanosponges.

\section{Introduction to antivirulence therapies}

Toxins represent a ranged attack mechanism employed by a variety of organisms to help aid in their survival. The more potent ones can have a large and immediate impact on human wellbeing, causing irreparable damage and oftentimes death. Toxin-secreting organisms are highly prevalent in nature, and notable examples include bacteria, snakes, and insects among many others [1]. In the case of bacterial infections, the role of toxins is to allow the pathogen to better colonize and survive within the hostile environment of a host [2]. Venomous eukaryotes employ toxins as defense mechanisms or to immobilize prey [3]. In total, these damaging molecules represent a major worldwide health problem that affects people regardless of 
socioeconomic status or geographic location $[4,5]$. They can even be mobilized as biological weaponry, with anthrax representing one of the more notable examples in recent history [6]. As such, the neutralization of toxins is of high importance, and a great deal of research has been focused on this subject.

Because of their damaging nature and the significant role that they can play in different pathogeneses, targeting toxins represents a rational means of treating afflictions on a causal level. For example, in the case of bacterial infections, which represent one of the most common causes of illnesses in the world, toxin neutralization serves to disarm the pathogens and remove the agents directly responsible for many of the worst symptoms [7, 8]. Due to the role of toxins in allowing pathogens to subvert immune defenses or obtain nutrients from nearby cells, detoxification also makes effective colonization of human hosts more difficult [9]. Further, antivirulence treatment strategies are less susceptible to resistance development, making them attractive alternatives to current therapeutic modalities [10]. This is largely due to the fact that they do not act on individual bacteria, lessening the Darwinian selection process that drives antibiotic resistance. Search for such robust treatments is becoming ever more important due to the rise of many antibiotic resistant bacterial strains that is far outpacing the development of new drugs $[11,12]$.

Conventional strategies for the neutralization of protein-based toxins have relied heavily on structure-specific platforms such as antibodies, which can be generated with high affinity against specific toxin species [13, 14]. However, because many organisms secrete multiple types of damaging toxins $[15,16]$, effective antivirulence treatment requires simultaneous administration of multiple formulations. Combined with the need to identify virulence species, clinical application of structure-specific antivirulence platforms can be difficult, thereby prompting the development of broadly applicable anti-toxin platforms.

Upon inspecting toxin mechanisms, it can be reasoned that cell membranes present the primary barrier that toxins need to overcome to inflict their virulence effect. Such mechanistic similarity offers the opportunity for developing broadly applicable anti-toxin formulations. Recent research efforts have demonstrated multi-toxin neutralization by employing nanoparticulates with lipid membrane interfacing [17, 18]. These emerging platforms take advantage of the fact that, regardless of their individual modes of action, all toxins must at some point interact with the cell membrane (Fig. 1). Further, nanoparticles inherently have properties 
that can benefit detoxification applications, including long circulation and the potential for multivalent toxin interaction. In light of these recent developments and their therapeutic implication, the present article reviews the evolution of cell-membrane mimicking nanoparticles with specific emphasis on toxin-related studies. Firstly, different mechanisms through which protein toxins interact, disrupt, and overcome the cell membrane barrier are described to highlight the role of the cell membrane interface in toxin actions. This is followed by an overview of the development of cell-membrane mimicking nanostructures and their application in protein toxin research as well as in biodetoxification. Finally, the implication of utilizing toxin-neutralizing nanocomplexes in antivirulence vaccination is discussed.

\section{Interactions between toxins and cell membranes}

To inflict their virulence effect on host systems, all toxins must interact in one way or another with cell membranes. Most often, toxins bind specific receptors on the cell surface, allowing them to effectively carry out their function. Once they make contact, there are several means by which toxins act. They can directly manipulate the membrane and its associated functions, or they can traverse the membrane barrier and disrupt intracellular processes.

\subsection{Binding of toxins to cell membranes}

Most toxins display a certain level of specificity towards individual components of cell membranes $[19,20]$. They can target specific biomolecules on the membrane surface such as proteins and lipids or they can be attracted by nonspecific interactions. This membrane affinity enables the toxins to carry out their biological function. Toxins can act directly on the membrane by causing physical disturbances or they can affect intracellular process such as protein synthesis, and their ultimate function often dictates the type of membrane moiety that is targeted $[21,22]$. Further, toxin receptors can be present on some cells but not on others [23, 24], allowing the toxins to impact specific physiological processes.

\subsubsection{Membrane-bound proteins}

Proteins located on the cell membrane surface represent a major class of targets utilized by toxins. The large diversity and uniqueness of surface proteins enable toxins to carry out a large variety of functions with high specificity. Surface proteins can be essential for the binding 
and structural maturation of toxins, as is the case with ADAM10, a sheddase that is conserved in many mammals and is the target of the pore-forming $\alpha$-hemolysin produced by the gram-positive bacterium Staphylococcus aureus [25]. The ability of $\alpha$-hemolysin to lyse erythrocytes is species dependent and highly correlated with expression of this protein receptor [25]. Transmembrane ion channels in the plasma membrane are common targets whose functions are directly affected by peptide toxins found in venoms [26]. Aerolysin, a pore-forming toxin secreted by the gramnegative bacterium Aeromonas hydrophila, targets extracellular proteins anchored by the lipid derivative glycophosphatidylinositol [27]. Binding to glypiated proteins enables toxins to more effectively oligomerize by localizing and concentrating individual monomers onto lipid rafts [28]. Other examples of membrane protein-binding toxins include anthrax toxin, which targets two different receptors on the cell surface [29], and phospholipases secreted by pathogens or in venom that, besides their affinity to their lipid-based substrates, are sometimes capable of binding to endogenous receptors on host cells [30].

\subsubsection{Lipid derivatives}

Lipid derivatives represent another major class of targets for toxins. Within this class of biomolecules, glycosylated lipids such as gangliosides, which contain sialic acid residues on their sugar chains, are the most common targets. For example, ganglioside GM1 is the receptor for numerous members of the $\mathrm{AB}$ toxin superfamily [21], including cholera toxin secreted by Vibrio cholerae [31], tetatnus toxin secreted by Clostridium tetani [32], and enterotoxin secreted by Escherichia coli [33]. On the other hand, the Shiga toxin family and Escherichia coli verotoxin target the ganglioside Gb3 [34]. The distribution of Gb3 within the body dictates many of the toxicities observed for these toxins [35]. One reason for the affinity of toxins for gangliosides is believed to be the propensity of these lipid structures to concentrate in membrane rafts, which allows the concentration of toxin molecules and can trigger signaling events that ultimately lead to intracellular trafficking of the toxins [36]. Besides the more common sugarmodified lipid derivative targets, toxins can also bind relatively unmodified lipids. An example is lysenin, a pore-forming toxin produced by the common brandling worm, which is highly specific to sphingomyelin [37]. It has been shown that, once bound, the oligomerization of lysenin monomers and subsequent pore formation is highly dependent on the fluidity of sphingomyelin within the membrane [38]. Phospholipases, which represent a broad category of hydrolytic 
enzymes, have natural affinity to their phospholipid substrates $[39,40]$. They are produced endogenously, but bacteria toxins can also have a large range of phospholipase activity [41], and phospholipase A2 is highly prevalent in venomous secretions [42, 43].

\subsubsection{Cholesterol}

The lipid cholesterol plays an important role for many toxins due to its impact on membrane fluidity and raft formation, which can aid in oligomerization and intracellular transport [44]. Besides this indirect role, cholesterol can also act as the receptor for certain types of toxins. The class of toxins known as cholesterol-dependent cytolysins (CDCs) form large pores in cellular membranes and require cholesterol for their action [45]. Perfringolysin O, produced by Clostridium perfringens, and streptolysin $\mathrm{O}$, produced by most strains of $\beta$ hemolytic group A streptococci bacteria, require cholesterol for binding. Because of their affinity for cholesterol, these toxins have even been used to study the formation of microdomains on the cell membrane [46]. Detailed studies have demonstrated that a two amino acid motif composed of threonine and leucine is essential for the recognition of cholesterol by this family of toxins [47]. Aside from CDCs, toxins such as cytolysin from Vibrio cholerae, which forms heptameric oligomers, are also cholesterol specific [48]. Others, including $\varepsilon$-toxin from Clostridium perfringens, have significantly reduced association with cell membranes upon cholesterol depletion, although the direct role of cholesterol in the binding of these toxins is unclear [49].

\subsubsection{Electrostatic interactions}

Electrostatic charge plays an important role in the binding of many toxins. Phospholipases can have high isoelectric points [50], making them positively charged in physiological conditions and enabling them to interact efficiently with negatively charged substrates $[51,52]$. The binding of ion channel blocking toxins, commonly found in venomous secretions of multicellular organisms such as snakes and insects, has also been shown to be highly dependent on electrostatic interactions [53]. Further, some toxins whose purpose is physical disruption of membrane do not require specific receptors, and solely employ charge as a means of binding. An example is melittin, a pore-forming peptide found in bee venom that contains a series of positively charged amino acid residues and has an overall positive charge at neutral $\mathrm{pH}$, enabling it to bind negatively charged membranes with high affinity [54]. 


\subsection{Modes of toxin-mediated action}

Once a toxin recognizes and associates with the cell membrane, there are several ways by which it can mediate its toxic effects (Fig. 2). One way is to directly act on the membrane, which can either occur by physical disruption such as pore formation or perturbation of membraneassociated processes such as the blockage of ion channels. Other toxins must traverse the cell membrane barrier after binding, and this is most commonly accomplished through endocytosis whereupon they can localize to their final targets. These toxin-mediated effects are largely responsible for the physiological symptoms observed in the clinic with respect to infections or venomous injuries.

\subsubsection{Disruption of membrane structure}

The direct formation of pores on cell membranes is one of the most common and wellstudied mechanisms of toxin action. Bacterial pore-forming toxins (PFTs) can broadly be categorized based on their structural characteristics, being composed largely of either $\alpha$-helices for $\alpha$-PFTs or $\beta$-strands for $\beta$-PFTs [55]. $\beta$-PFTs are by far more common among bacteria and share many conserved characteristics. A large number of $\beta$-PFTs form heptameric pores, and these include $\alpha$-hemolysin from Staphylococcus aureus [56], aerolysin from Aeromonas hydrophila [57], and cytolysin from Vibrio cholerae [58]. The formed pores are small in size, averaging between $1.5 \mathrm{~nm}$ and $3 \mathrm{~nm}$ in diameter [19]. CDCs are another group of $\beta$-PFTs, but form much larger pores that are between $35 \mathrm{~nm}$ and $50 \mathrm{~nm}$ in diameter [19]. Pore formation generally occurs in multiple steps, with structural changes often accompanying oligomerization [59]. In many cases, protoxins must be enzymatically converted to active toxins before pore formation can occur [60]. The process of oligomerization may also be necessary for toxins that require cooperative action among monomers to initiate pore formation [61]. Other than bacteria, numerous species also secrete toxins that can directly form pores on the membrane surface. Some notable examples include cardiotoxin A3 produced by the Taiwanese cobra Naja atra [62], melittin found in venom of the honeybee Apis mellifera [63], and lysenin secreted by the earthworm Eisenia fetida [37].

While PFTs literally poke holes into the membrane of cells, phospholipases disrupt the membrane through the degradation of the membrane's main structural constituents. This process 
is useful for a variety of purposes, ranging from aiding in the digestion of prey [64] to creating a favorable niche in which bacteria can grow [41]. Much like pore-formation, the damage caused by phospholipases can result in cytolysis, which is responsible for many of the virulent effects caused by these toxins [41]. Due to significant homology between endogenous phospholipases and those secreted by other organisms, binding can be localized to specific areas of the body [30]. While these toxins are generally a characteristic component of venoms, various singlecelled organisms also employ them to great effect. It is believed that $\alpha$-toxin from Clostridium perfringens helps to promote anaerobic growth by damaging surrounding vasculature [65], and Helicobacter pylori secretes different phospholipases that enable them to more effectively colonize at low $\mathrm{pH}$ values in the stomach [66]. The toxins are also secreted by many types of fungi, and the level of secretion has been shown to correlate well with virulence [67].

\subsubsection{Perturbation of membrane-associated processes and signaling}

Besides physical disruption, toxins can also mediate their effects on host systems by disturbing processes and signaling originating at the cell membrane surface. One class of potent toxins, known as superantigens, have the ability to crosslink the major histocompatibility II molecules found on antigen presenting cells with $\mathrm{T}$ cell receptors [68]. This crosslinking mediates a variety of signaling events that culminate in the non-specific activation of large numbers of T cells [69]. The result of this over-activation is the systemic flood of cytokines, which can have devastating effects on the host and cause toxic shock syndrome. The most well studied superantigens are those secreted by the bacteria Staphylococcus aureus and Streptococcus pyogenes [70]. Besides superantigens, toxins such as heat-stable enterotoxins produced by some Escherichia coli have the ability to turn on the function of membrane-bound enzymes like guanylate cyclase, which results in modulation of downstream intracellular signaling [71].

Other toxins act on the membrane level by restricting access of receptors to their normal substrates. Prime examples are the neurotoxins found in snake venom that restrict access to the neurotransmitter molecule acetylcholine [72]. $\alpha$-Neurotoxins are antagonists of nicotinic acetylcholine receptors, with notable examples being the cobratoxins found in the venoms of the Naja genus and $\alpha$-bungarotoxin produced by the many-banded krait [73]. Once bound to the receptor, these toxins prevent the action of acetylcholine and ultimately cause paralysis. On the 
opposite end, fasciculins, which are produced by the green mamba Dendroaspis angusticeps, inhibit acetylcholinesterases [74]. Once bound to the receptor, hosts lose the ability to degrade acetylcholine, which leads to loss of muscle control.

Beyond affecting small molecule receptors, neurotoxins can also act by blocking ion channels. These toxins bind specifically to certain transmembrane channels, causing disruption of ion gradients that can lead to either hyperpolarization or depolarization of membrane potentials [75, 76]. This can affect a variety of processes such as intracellular signaling, regulation of cell volume, and neurotransmission [77]. Notable examples include chlorotoxin of the deathstalker scorpion Leiurus quinquestriatus [78], dendrotoxin produced by mamba snakes in the Dendroaspis genus [79], and tetrodotoxin, which is found in several different types of animals but is actually produced by symbiotic bacteria [80]. The binding specificity of different ion channel blocking neurotoxins has been leveraged as a tool for studying the function of these important membrane proteins [81].

\subsubsection{Disruption of intracellular processes via membrane traversal}

Many toxins, instead of acting directly on the surface of cells, must cross the plasma membrane barrier in order to take action. These types of toxins generally contain multiple subunits or domains that separately carry out binding, entry, and catalysis functions. To accomplish entry, most take advantage of native cellular processes such as endocytosis [36]. Employment of this indirect approach is likely due to the fact that direct entry from the cell surface is disruptive and too traumatic of an event. One of the only exceptions to this is adenylate cyclase toxin produced by the bacterium Bordetella pertussis that is responsible for whooping cough; in this case the catalytic domain is translocated across the plasma membrane directly into the cytoplasm [82].

Most membrane traversing toxins follow a binary $\mathrm{AB}$ format, where the $\mathrm{B}$ subunit is responsible for binding and entry while the A subunit represents the toxic catalytic component [83]. They can be divided into those that employ either short or long pathways for access [19]. Short pathway toxins directly escape from the endosome to gain access to the cytoplasm. Anthrax toxin produced by Bacillus anthracis is an example of such a toxin, where the B subunits form a pore once triggered by the endosomal environment, leading to transport of the A subunit into the cytoplasm [29]. Single chain toxins such as diphtheria toxin secreted by 
Corynebacterium diphtheriae employ a different mechanism, whereby the B subunit has a translocation domain that helps to chaperone the A subunit directly across the membrane [84].

Long pathway toxins employ retrograde transport in order to deliver the catalytic subunit to the appropriate location. Instead of directly escaping from the endosome to the cytoplasm, these toxins are retrogradely trafficked first to the trans-Golgi network and then the endoplasmic reticulum (ER) [85]. Shiga toxins, produced by Shigella dysenteriae and various Escherichia coli, are catalytically activated during this transport process and gain access to the cytoplasm via the ER, where they then disrupt protein synthesis by binding to ribosomes [86]. Other toxins that follow similar routes include ricin found in castor beans [87] and cholera toxin from Vibrio cholerae [88]. In most cases, B subunits are not directly responsible for translocation into the cytoplasm, and the A subunits require molecular chaperones and endogenous translocation channels for this purpose [89].

\subsubsection{Type III secretion}

Type III secretion represents a unique type of membrane traversal mechanism employed by bacteria in which a pathogen directly secretes toxins through a needle complex, or

injectisome. For Shigella flexneri, one of the better studied organisms that employ such a system, the tip of the protrusion is characterized by proteins that have been shown to display affinity towards cholesterol and lipid rafts [90]. Cholesterol depletion can abrogate translocation of effector units across the target's plasma membrane [91]. Upon coming into contact with a host cell, the Ipa series of the proteins are responsible for binding and pore formation, the result of which is similar to that of traditional PFTs [92]. Type III secretion is commonly found in different bacteria, and is present in species of Shigella, Salmonella, Vibrio, and Yersinia among others [93].

\section{Cell-membrane mimicking nanoparticles for toxin neutralization}

Owing to the close connections between many toxins' virulence mechanisms and cellular membranes, many lipid-based cell membrane mimics have been applied as decoys to preoccupy and neutralize toxin actions. Nanocomplexes comprising of phospholipid bilayers have been prepared to either serve as toxin substrates or to carry toxin-specific receptors for antivirulence therapy. The dynamic nature of phospholipids enables facile preparation of these 
nanoparticulates. The fluidity of lipids in cell-membrane mimicking nanostructures also allows particle functionalization with a variety of biomolecules. The biomimetic nature of many lipidbased nanostructures has drawn significant interest in their application for the elucidation of toxin mechanisms as well as for the neutralization of several virulence factors. Towards clinical translation, mechanism-based, broadly applicable treatments have the potential to speed up treatment and improve outcomes in cases of acute venomous injuries, as specific toxin identification is less critical. Further, the long circulation of many nanoparticle platforms can facilitate more effective toxin sequestration in diseases that entail prolonged exposure. The following section summarizes previous protein toxin research involving lipid-based nanostructures, with an emphasis on formulations designed for toxin neutralization.

\subsection{Liposomes}

Liposomes, which encapsulate a region of aqueous solution within a hydrophobic bilayered membrane, are most recognized as versatile carriers of therapeutic compounds for systemic delivery. As liposomes in many ways mimic the properties of cell membranes, these nanostructures were used extensively as model membranes to elucidate the action mechanisms of major bacterial toxins. Studies on the interactions between synthetic liposomes and membraneactive toxins can be dated back to 1965, in which Bangham et al. demonstrated that streptolysin$\mathrm{S}$, a streptococcal hemolytic exotoxin, modulated cation permeability of multilamellar $150 \mathrm{~nm}$ liposomes [94]. The concept was further examined in a subsequent study in which staphylococcal $\alpha$-toxin was found to increase ion permeability of liposomes [95]. Following these early studies, liposomes were frequently used to examine the mechanisms and properties of different membrane-active toxins. Examples of these toxins include bacterial virulence factors, such as streptolysin-O [96], diphtheria toxin [97, 98], aerolysin [99], pneumolysin [100], cereolysin [101], and tetanolysin [102], and toxins from animals and plants, such as cardiotoxin from snake venom [103] and melittin from bee venom [104]. Owing to their structural fluidity and compositional modularity, liposomes can be readily functionalized with special lipids, sterols and other complex biomolecules, such as glycoproteins and glycolipids, to enhance toxin affinity. These liposomal formulations have become one of the most common tools in the study of protein toxins $[105,106]$. 
While these mechanistic studies focused primarily on the identification of toxin components and elucidation of virulence mechanisms, they demonstrated that nanoscale synthetic liposomes can be applied as toxin substrates for emerging biomedical applications. For example, ganglioside-bearing liposomes have been applied for ultrasensitive detection of botulinum, tetanus, and cholera toxins [107]. These cell membrane mimics, composed of synthetic lipids along with gangliosides of the G1b series and GM1, facilitated the formation of toxin/liposome complexes, and the resulting nanocomplexes yielded enhanced toxin detection sensitivity in colorimetric, immunological, and electrochemical assays as compared to free toxin molecules [108-110]. Another notable example that exploits liposome/toxin interaction is the implementation of bacterial toxin-triggered drug release for antibiotics delivery. Motivated by the promise of targeting therapeutic payloads to the site of bacterial infection, it has been shown that drug-loaded liposomes selectively released their payloads in the presence of bacterial toxins $[111,112]$. The targeted drug release is triggered by the pore-forming $\alpha$-hemolysin, which serves to perforate the membrane bilayers of $110 \mathrm{~nm}$ liposomal carriers, which were comprised of egg phosphatidylcholine and cholesterol. Following this concept, Thamphiwatana et al. demonstrated phospholipase-triggered liposomal drug release for the treatment of Helicobacter pylori [113]. These examples highlight some of the unique applications of liposomes in the management of toxin-secreting bacteria.

More recently, Henry et al. demonstrated direct neutralization of bacterial exotoxins with liposomes (Fig. 3). Liposomes were formed by drying the lipids into a film and then reconstituting the lipids in Tyrode's buffer $(140 \mathrm{mM} \mathrm{NaCl}, 5 \mathrm{mM} \mathrm{KCl}, 1 \mathrm{mM} \mathrm{MgCl}, 10 \mathrm{mM}$ glucose, $10 \mathrm{mM} \mathrm{HEPES}$ ) and $2.5 \mathrm{mM} \mathrm{CaCl}_{2}$. The hydrated film was then vortexed vigorously and sonicated to form the final liposomes. Using liposomal formulations, at a dosing of 100 $\mathrm{mg} / \mathrm{kg}$, containing sphingomyelin only or sphingomyelin with cholesterol at a 2-to-1 molar ratio, the authors successfully neutralized a number of major bacterial virulence factors, including pneumolysin, staphylococcal $\alpha$-hemolysin, tetanolysin, streptolysin-O, phospholipase $\mathrm{C}$, as well as crude bacterial supernatants [18]. The toxins were found to be sequestered by the $130 \mathrm{~nm}$ liposomes, and they were thereby precluded from interacting with cellular targets. In mouse models of intranasal and intravenous infections with Streptococcus pneumonia, treatment with the engineered liposomes were found to reduce overall bacterial load as well as to extend the overall subject survival. The anti-toxin liposomes were also applied as an adjunct therapy to 
complement conventional antibiotics, such as vancomycin and penicillin, in treating fatal Staphylococcus aureus and Streptococcus pneumonia infections in mice. Combinations of liposomes and antibiotics resulted in superior overall survival as compared to mono-therapies using antibiotics alone. Intravenous administration of the artificial liposomes along with vancomycin or penicillin within $10 \mathrm{~h}$ after infection rescued the mice from septicemia caused by S. aureus and S. pneumoniae, while untreated mice died within $24-48 \mathrm{~h}$. The study validated the use of liposomes as a toxin decoy in vivo, offering evidence that disease burden of bacterial infections can be reduced via removal of secreted virulence factors. Further, as these liposomes are made only from naturally occurring lipids without a synthetic polymer outer layer, it can be reasoned that the risk of unwanted immune reactions that have been observed for clinical liposomal formulations should be lessened [114].

Functionalization with specific receptor molecules may also increase the applicability of anti-toxin liposomes against toxins with unique receptor specificity. Basha et al., for instance, functionalized liposome surfaces with peptides possessing high affinity to an anthrax toxin. High affinity peptides were identified using phage display and subsequently conjugated onto DSPC/DSPE liposomes via a thiol reaction. Owing to the polyvalency effect, the resulting liposomes had a 50,000-fold increase in toxin affinity as compared to free peptides [115]. A 400 nmol intravenous dose of the peptide-conjugated liposome was able to prevent moribundity of rats infected with lethal anthrax toxin. The membrane fluidity of liposomes may also provide a unique and favorable microenvironment for the binding of pathogenic material. As the high binding affinity between a pathogenic ligand and its receptor occurs only within the highly differentiated niche of the lipid membrane microenvironment [116], the lipid bilayer of liposomes has the potential to provide this specific environment via the modulation of conformational equilibria of receptors. With the recent developments in liposomes, the physicochemical properties of membrane bilayers may be finely tuned to enhance their efficacy in different anti-toxin applications.

\subsection{Reconstituted lipoprotein nanostructures}

In addition to liposomes, reconstituted lipoprotein can also be used in the construction of antipathogenic decoys. Reconstituted lipoprotein nanostructures, which are approximately $10 \mathrm{~nm}$ in height and 10-20 $\mathrm{nm}$ in diameter, display significant stability in vivo [117] and present a 
viable way to mediate receptor clustering [118]. Lipoproteins are naturally present in the body as a discoidal patch of lipid membrane bounded by apolipoprotein A-I. Using their constituent components, these particles can be reconstituted and assembled spontaneously via proteolipidic self-assembly [119]. This method allows for engineering of lipoprotein composition at the molecular level, opening the door for any number of membrane-compatible components to be included in the nanoparticle. Proton pumps [120, 121], membrane-associating enzymes [122], and signaling proteins $[118,123]$ have all been successfully incorporated into lipoprotein nanostructure.

Natural lipoproteins have been observed to spontaneously interact with membrane-active toxins, frequently leading to inhibition of the toxin activity. The lytic actions of staphylococcal hemolysins [124], streptolysin-O [125], asp-hemolysin from Aspergillus fumigatus [126], and a Stoichactis helianthus toxin [127] have been shown to be abrogated in the presence of serum lipoproteins. This inhibitory action can be attributed to the presence of stabilized lipid microdomains in lipoproteins, which are also rich in toxin receptor contents such as cholesterol and sphingomyelin. Toward developing anti-toxin formulations for clinical use, reconstituted high-density lipoprotein (rHDL) has been engineered to incorporate ganglioside GM1 to increase affinity to certain pathogenic ligands (Fig. 4) [128]. Composed of 1,2-dimyristoyl-sn-glycero-3phosphocholine (DMPC), 1,2-dioleoyl-sn-glycero-3-phosphocholine (DOPC), sphingomyelin, cholesterol, and GM1 ganglioside vesicles associated with human apolipoprotein A-I, these GM1-laden rHDL nanocomplexes were able to bind cholera toxin with higher affinity than soluble analogs of GM1 [128,129]. In vitro, the modified rHDL nanocomplexes significantly reduced cholera toxin attachment to human epithelial cells, successfully acting as decoys to prevent negative outcomes associated with cholera toxin binding to host cells. Sheng et al. used a similar strategy to adsorb autoantibodies associated with myasthenia gravis by incorporating acetylcholine receptors onto rHDL and treating mice at a dosage of $15 \mu \mathrm{g}$ of nanoformulation per injection [130].

One possible limitation of the engineered rHDL platform for anti-toxin application arises from the potential interaction of pathogen decoys with host cells and tissues. The presence of pathogen decoys within the cytoplasm may be harmful to the cell, and the exact fate remains unknown. Additionally, the decoys must be able to reside within the blood, gastrointestinal tract, or other epithelial compartments for enough time to perform their protective function before 
being cleared by the reticuloendothelial system. The most promising method to overcome the hurdle of unintended host interaction involves functionalizing the surface of the lipid membrane with molecules that impede host binding via steric, electrostatic, or biochemical interactions [131]. For this purpose, glycolipids with charged or neutral head groups and large membraneanchored proteins can be used to provide biochemical and steric barriers, respectively. Further work along the lines of rHDL-host interactions and how to mitigate the toxicity of such nanoformulations is necessary prior to clinical translation of rHDL as a pathogen decoy candidate.

\subsection{Cell membrane-derived nanostructures}

Cell membrane-derived nanostructures present an appealing platform for toxin neutralization as protein toxins have evolved to exploit the numerous moieties on cell membrane surfaces. While synthetic liposomal structures can be easily modified with specific functionalities, it has proven difficult to mimic or replicate the complex protein functionalities and compositions in their entirety found in natural systems [132]. Increasing effort has been put into utilizing natural cell membrane-derived vesicles for drug delivery and other biomedical applications. These naturally derived vesicles have the advantage of retaining many of the natural functionalities of the source material, thereby allowing each system to possess unique characteristics that would otherwise be difficult to achieve [133]. In addition, genetic alteration can be used to modify the antigen profile of natural membranes to better suit different uses [134, $135]$.

Toward developing biomimetic anti-pathogen decoys, de Carvalho and colleagues showed that exosomes released from CD4+ T cells, but not from CD4- T cells, can strongly inhibit HIV-1 infection in a concentration dependent manner in vitro [136]. These exosomes display the same complex surface protein makeup as their parent T cells, allowing them to successfully bind to HIV-1, thereby diverting the virus away from healthy cells. By mimicking host cells, host-derived membrane vesicles can act as decoys to inhibit parasite and bacterial invasion of host cells as well [137].

As many major bacterial virulence factors and animal venom toxins are known for their ability to lyse red blood cells (RBCs), RBC-derived membrane vesicles have been commonly used as a biological membrane model in examining the dynamics of protein toxins $[25,96,138]$. 
Deprived of their intracellular content, these membrane vesicles retain the lipids, proteins, and glycans of their source cells [139], thereby allowing for toxin interactions in a biomimetic manner. Recent efforts have focused on the derivation of nanoscale particulates based on membranes derived from natural cells $[140,141]$. These biomimetic nanoparticles provide emerging opportunities in toxin neutralization strategies.

In developing a biomimetic anti-toxin platform that neutralizes membrane-disrupting toxins, $\mathrm{Hu}$ and colleagues showed that polymeric nanoparticles wrapped in a RBC membrane "cloak" are able to act as a toxin "nanosponge" and divert pore-forming toxins away from their healthy cellular targets (Fig. 5) [17]. To prepare these RBC membrane-cloaked nanoparticles, $\mathrm{RBC}$ membranes purified from whole cells were mixed with polymeric nanoparticles prepared from poly(lactic-co-glycolic acid). Mechanical extrusion was subsequently applied to promote $\mathrm{RBC}$ membrane adsorption onto the surface of the polymeric core [141]. The resulting $85 \mathrm{~nm}$ nanoparticles were shown to retain the majority of RBC membrane antigens and display them in a right-side-out fashion [142, 143]. Owing to the substrate-supported lipid membrane structure, the cell membrane is stabilized by the nanoparticle interior. This nanoparticle-induced stabilization was shown to be an important factor in nanoparticles' ability to neutralize poreforming toxins. In comparison to unsupported RBC membrane vesicles, the RBC membranecloaked nanoparticles were not prone to membrane fusion and thus would not transfer sequestered toxins to host cells. Examination under transmission electron microscopy also revealed that the stabilized membrane retained its unilamellar conformation following toxin interaction. The platform was demonstrated to inhibit the hemolytic activity and cellular toxicity of multiple pore-forming toxins, including staphylococcal $\alpha$-hemolysin, streptolysin-O, and melittin. It was found that $500 \mu \mathrm{g}$ of nanosponges could neutralize $11 \mu \mathrm{g}$ of $\alpha$-hemolysin, $7.2 \mu \mathrm{g}$ of streptolysin-O, or $9.1 \mu \mathrm{g}$ of melittin.

The RBC membrane coating also bestowed onto the nanoparticles extended circulation half-life that is beneficial toward the platform's in vivo application [141]. In a mouse model challenged intravenously with a lethal dose of staphylococcal $\alpha$-hemolysin, the RBC membranecloaked nanoparticles, at a dosing of $80 \mathrm{mg} / \mathrm{kg}$, significantly reduced the toxin's toxicity and offered a survival advantage. Sequestered toxins were found to be safely metabolized in the liver as they were precluded from interacting with other cellular targets. Thus far, studies have shown that these nanoparticles are safe and biocompatible with no observable toxicities, although 
further, more in-depth studies are warranted prior to translation. By exploiting the natural membrane interface of cells, the RBC membrane-cloaked nanoparticle platform enables broadly applicable toxin neutralization based on the toxin's innate virulence mechanism. The cell membrane cloaking approach has already been extended to other cell types such as leukocytes [144] and cancer cells [145]. In addition, these biomimetic decoys were shown recently to have therapeutic implications in treating autoimmune diseases, as they were capable of absorbing and neutralizing auto-reactive antibodies [146]. The cell-membrane cloaked nanoparticle platform presents a unique integration of natural and synthetic biomaterials that offers a new paradigm for the design and application of nanomedicine.

\section{Anti-toxin nanoparticles in toxoid vaccine development}

As cell-membrane mimicking nanoparticles are able to sequester protein toxins in their natural conformation, the resulting inhibited particle/toxin nanocomplex has significant implications in the development of toxoid vaccines. Inactivated toxins have been administered to mount anti-toxin immune responses for managing bacterial infections. Notable toxoids currently used in clinics include tetanus, botulism, and diphtheria vaccines, which are prepared by modulating the primary virulence factors derived from their respective pathogens [147]. Ongoing efforts continue to focus on developing emerging toxoid formulations to help combat the rising threat of bacterial infections. However, an inherent tradeoff between safety and efficacy in conventional toxoid preparation approaches presents a major limitation to toxoid development. Toxoid preparation typically relies on chemical or heat treatments, which disrupt the proteins' tertiary structure and can lead to altered antigenic presentation and compromised immunogenicity [148, 149]. More recent efforts in toxoid development have focused on subverting a toxin's virulence while preserving its native structure, thereby improving both the vaccine's potency and its safety. In one example, Jones et al. implemented a chemical strategy to produce a non-toxic toxoid that was much more structurally and antigenically similar to native toxin than with formaldehyde treatment. This method was able to reduce the neurotoxic activity of botulinum neurotoxins by more than 7 orders of magnitude while increasing the neutralizing antibody levels by more than 600-fold compared with toxoids produced using formaldehyde [150]. Mice immunized subcutaneously with $15 \mu \mathrm{g}$ of the new toxoid were better protected against a challenge by botulinum toxin. Recombinant protein engineering has been used to 
prepare non-virulent toxin mutants that have demonstrated strong therapeutic efficacy in animal models and have entered human clinical trials [151-154]. These encouraging results suggest that toxoids can be more effective when prepared using minimally disruptive detoxification methods that more faithfully preserve the toxin's epitopic expression.

Toxin sequestration by nanoparticles provides the opportunity to deprive toxins of their virulence functions without compromising their immunogenicity. In a study that demonstrates the concept of toxin detainment by nanoparticles for vaccine preparation, $\mathrm{Hu}$ and colleagues showed that the spontaneous complexation between RBC membrane-cloaked nanoparticles and pore-forming toxins provided a facile method for preparing safe and potent vaccines (Fig. 6) [155]. The nanoparticle carriers bestowed a number of advantages conducive to the immune processing of toxin antigens. First, the toxins were presented to immune cells in their natural unaltered form. Second, the nanoparticles' stability and small size facilitated antigen delivery to lymphatic organs such as the spleen and lymph nodes. Third, the nanoparticle vectors were primarily taken up by cells via endocytosis, thus promoting toxin localization and metabolism in endolysosomal compartments. These factors contributed to the enhanced humoral response and safety exhibited by the nanoparticle-detained toxin. Using staphylococcal $\alpha$-hemolysin as a model toxin, the authors demonstrated that mice vaccinated with $200 \mu \mathrm{g}$ of the $75 \mathrm{~nm}$ nanoparticle (carrying $3 \mu \mathrm{g}$ of toxin) generated significantly higher anti-toxin titers compared to those vaccinated with heat-denatured toxin. The effective virulence removal and superior antitoxin immunity supported the advantages of applying toxin-sequestering nanoparticles for vaccine development.

As most toxins require precise cellular distributions and specific receptor interactions to take effect, altering their biodistribution and confining their molecular freedom using nanoparticulate vectors provide a non-disruptive way to deliver intact toxins for immune processing. It has also been observed that direct encapsulation of animal venoms using liposomes significantly reduced toxicity, and the resulting formulations were effective at raising anti-venom antibodies [156-158]. While nanoparticle-sequestered toxin has several advantages over conventional toxoid preparations, formulations containing non-denatured toxins inevitably raise safety concerns. Thorough studies are warranted prior to clinical translation of these emerging nanotechnologies. 


\section{Conclusions}

Conventional anti-toxin approaches have relied primarily on structure-specific platforms such as anti-sera and antibodies for toxin neutralization. While effective, these formulations have proven to be impractical to administer at times and often require explicit identification of the pathogenic species. Amidst the rising threat of drug-resistant bacteria as well as increasing awareness of animal envenoming, broadly applicable anti-toxin formulations possess significant therapeutic potential. Increasing understanding of protein toxins has provided a clear picture of the different virulence mechanisms, most of which are aimed at disrupting or bypassing the cell membrane interface. Advances in nanotechnology have yielded many cell-membrane mimicking nanoformulations, including liposomes, reconstituted lipoprotein, and cell membrane-derived nanoparticles. Significant efforts have been undertaken to elucidate the interaction between these nanostructured lipid membranes and protein toxins, and successful neutralization of major virulence factors has been demonstrated via precise formulation engineering. These nanoparticles can be administered in vivo to reduce disease burden in bacterial infections and animal envenoming. In addition, toxin sequestration by membrane-based nanoparticles has broad implications in the design of safe and effective toxoid vaccines. While further studies are needed to examine the long-term effect of nanoparticle-sequestered toxins and to expand applicability towards different routes of administration, the vast therapeutic potential of these lipid membranebased platforms is poised to shift the paradigm in disease management involving virulent toxins.

\section{Acknowledgement}

This work is supported by the National Institute of Diabetes and Digestive and Kidney Diseases of the National Institutes of Health under Award Number R01DK095168 and by the Defense Threat Reduction Agency Joint Science and Technology Office for Chemical and Biological Defense under Grant Number HDTRA1-14-1-0064. 


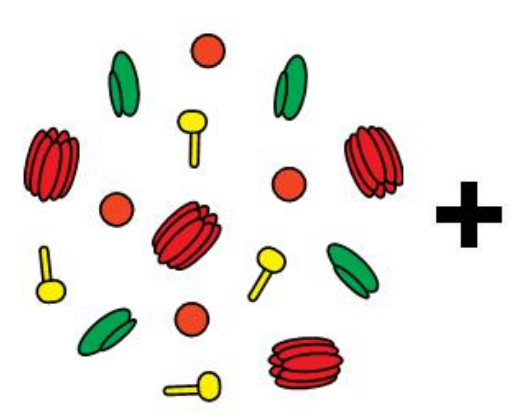

Protein toxins

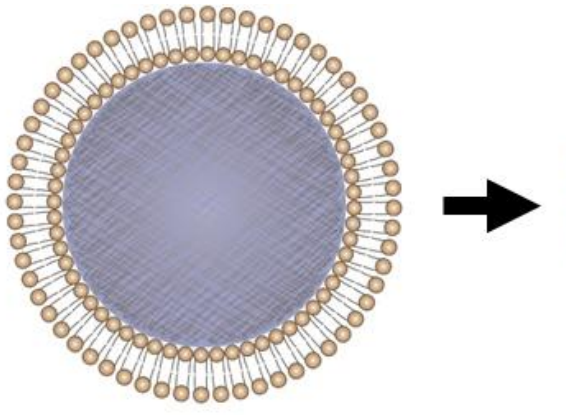

Cell-membrane mimicking nanoparticles

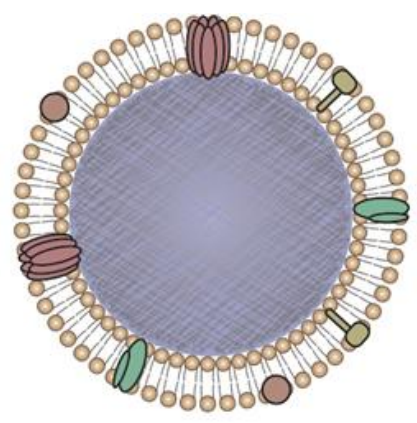

Nanoparticleneutralized toxins

Fig. 1. Engineered nanoparticles for detoxification aim to mimic natural cellular membrane structures. By closely imitating natural cellular surfaces, such nanoparticles have the ability to bind protein toxins. These nanoparticles effectively divert toxins away from healthy cellular targets and allow for safe metabolism and elimination of the protein toxins. 

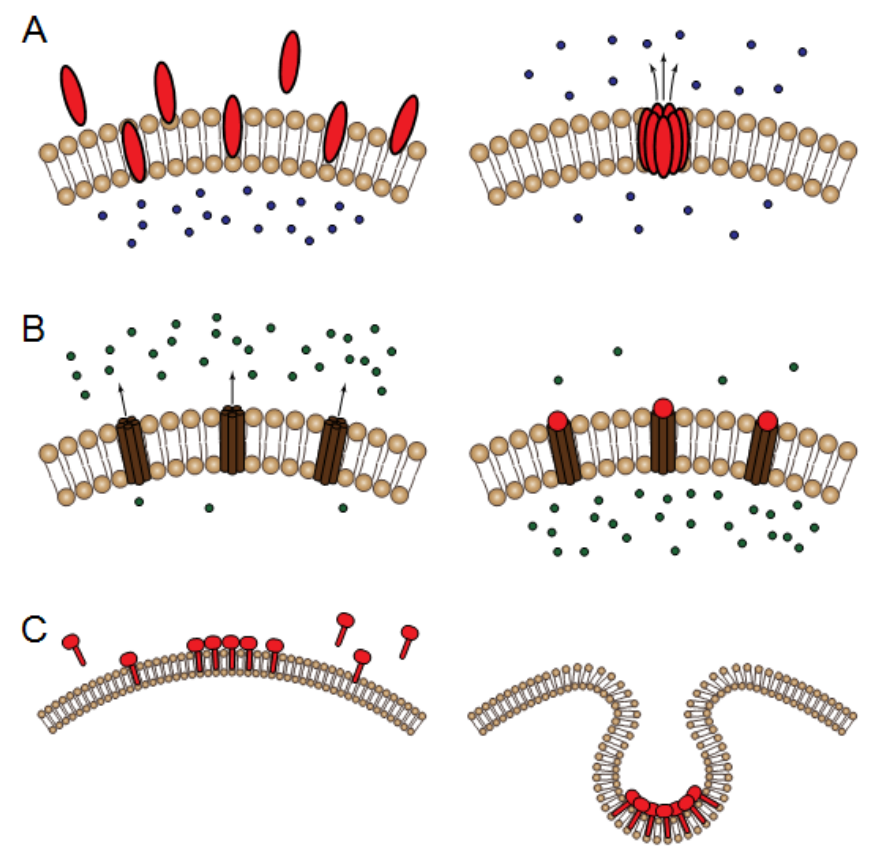

Fig. 2. Modes of toxin-mediated action on the cell membrane level. (A) Direct physical disruption leads to loss of membrane integrity (i.e. pore-forming toxins (red ovals) releasing intracellular contents (purple dots)). (B) Perturbation of membrane-associated processes leads to imbalances and alteration of signaling pathways (i.e. ion channels (brown structures) being blocked by toxins (red dots), leading to a change in ion gradients (green dots)). (C) Intracellular toxins traverse the plasma membrane barrier in order to gain access to their targets (i.e. binary toxins (red structures) via endocytosis). 
A
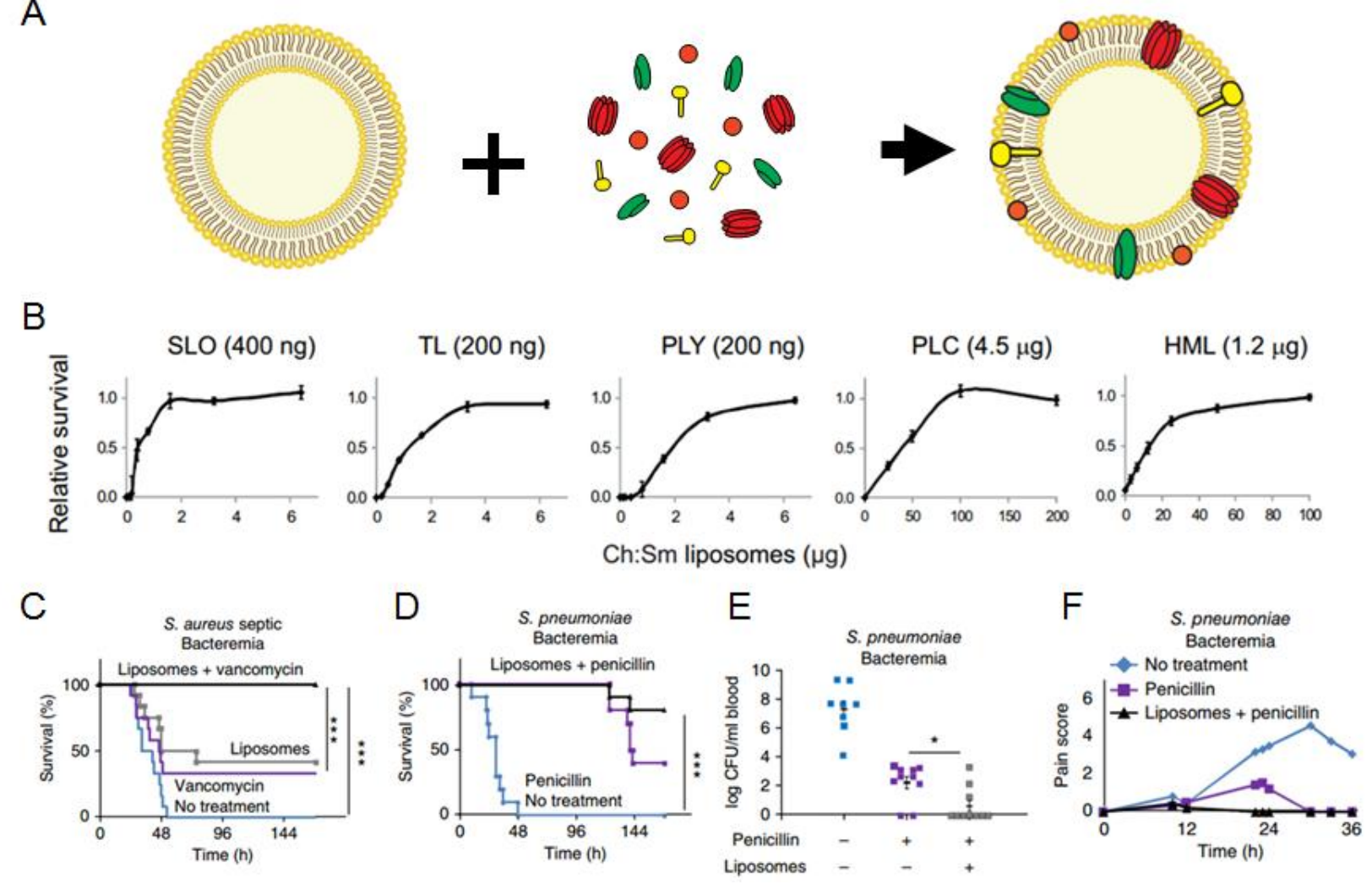

Fig. 3. Engineered liposomes sequester bacterial exotoxins. (A) Artificial liposomes composed of naturally occurring lipids are able to bind to a number of different cytotoxic pore-forming toxins. (B) Complete protection of monocytes against 200-400 ng of cholesterol-dependent cytolysins (SLO, streptolysin-O; TL, tetanolysin; PLY, pneumolysin) was observed at 2-4 $\mu \mathrm{g}$ of cholesterol:sphingomyelin liposomes; $100 \mu \mathrm{g}$ liposomes was able to neutralize $4.5 \mu \mathrm{g}$ phospholipase C (PLC); $50 \mu \mathrm{g}$ liposomes was able to neutralize $1.2 \mu \mathrm{g} \alpha$-hemolysin (HML). Viability (relative survival) of cells was normalized according to controls. (C,D) Liposomes administered with antibiotic improved the survival of mice infected with a septic strain of $S$. aureus bacteria (C) and S. pneumoniae (D). (E,F) Liposomes administered with antibiotic reduced the bacterial load found in the blood $(\mathrm{E})$ as well alleviated visible disease signs $(\mathrm{F})$. Reprinted with permission from [18]. 
A

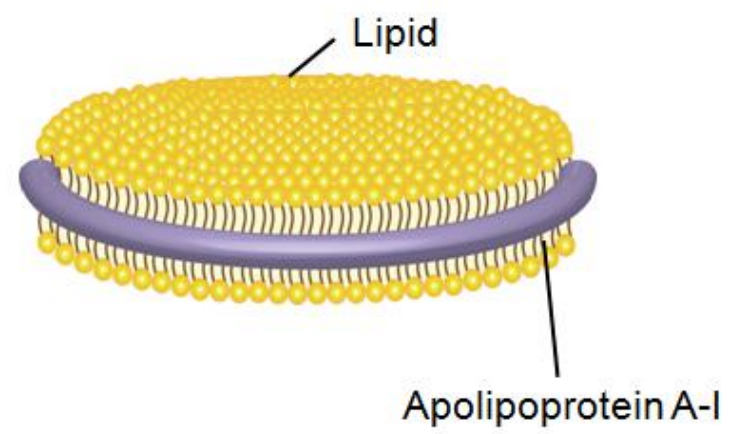

B
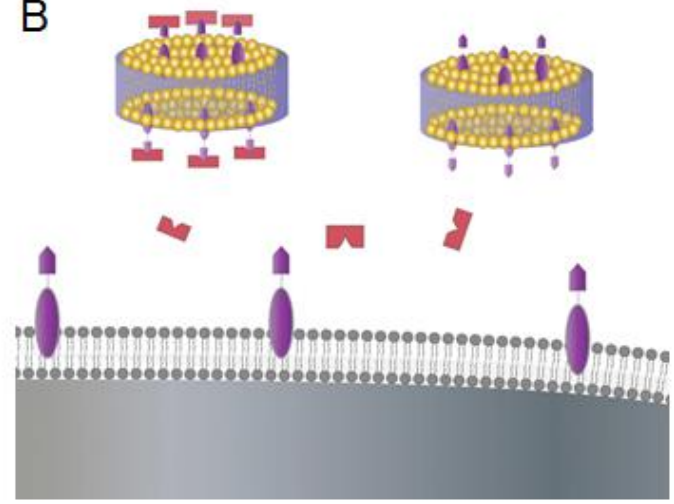

C

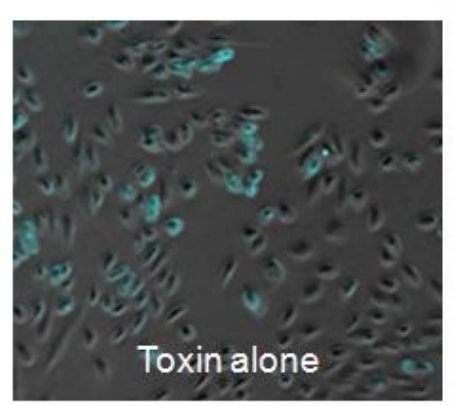

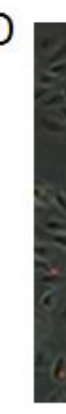
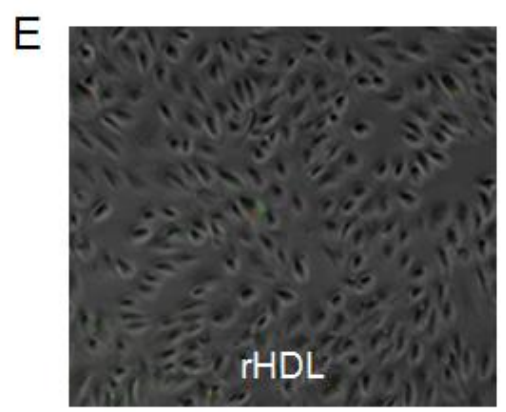

Fig. 4. Reconstituted high-density lipoproteins (rHDL) as toxin decoys. (A) rHDL consists of a discoidal patch of lipid membrane bounded by apolipoprotein A-I. (B) rHDL embedded with ganglioside monosialotetrahexosylganglioside (GM1) (purple) can act as decoys for soluble toxins such as cholera toxin (red) to protect live cells (gray). (C-E) Human retinal epithelial cells, as a model target cell line, incubated with cholera toxin B only (CTB) (C), toxin + vesicles (D), or toxin + rHDL (E). Cells appear in gray with NBD-labeled rHDL in green, Alexa594-CTB in red, and FITC-CTB in cyan (C only). Vesicles afford little protection from toxin while rHDL provide virtually complete protection. Reprinted with permission from [128]. 

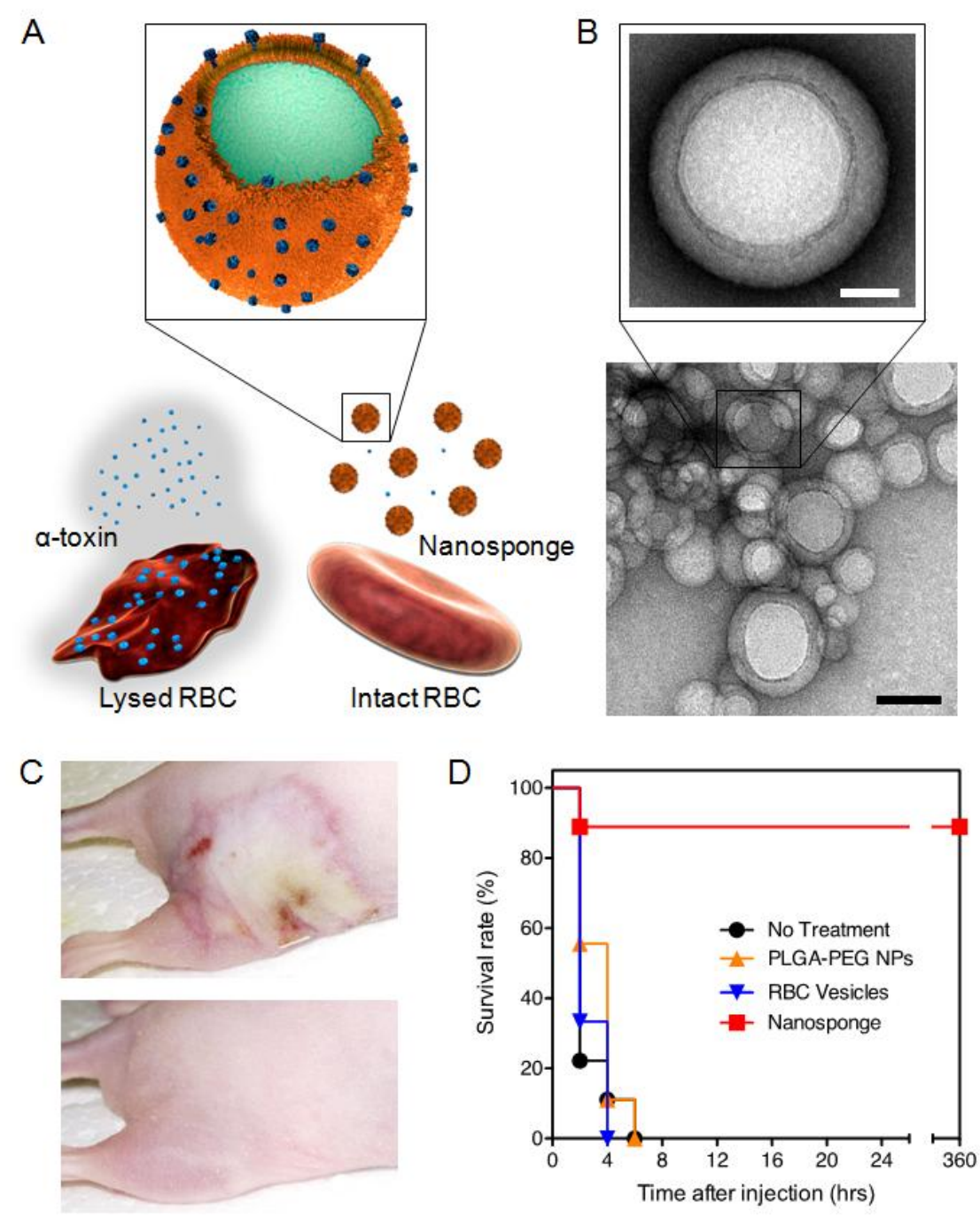

Fig. 5. RBC membrane-coated nanosponges for systemic toxin neutralization. (A) Schematic depicts the function of RBC membrane coated nanoparticles (denoted nanosponge) as toxin decoys. (B) Transmission electron microscopy (TEM) visualization of the nanosponges following interactions with staphylococcal $\alpha$-hemolysin. (C) Mice injected subcutaneously with $\alpha$-hemolysin only (top) or $\alpha$-hemolysin with nanosponges (bottom). Nanosponges provided full protection against lesion formation. (D) Survival rates of mice over 15 days following injection of nanosponge, PEGylated nanoparticles, or RBC vesicles, along with $\alpha$-hemolysin. Nanosponge administration conferred significant survival advantage to the mice. Reprinted with permission from [17]. 

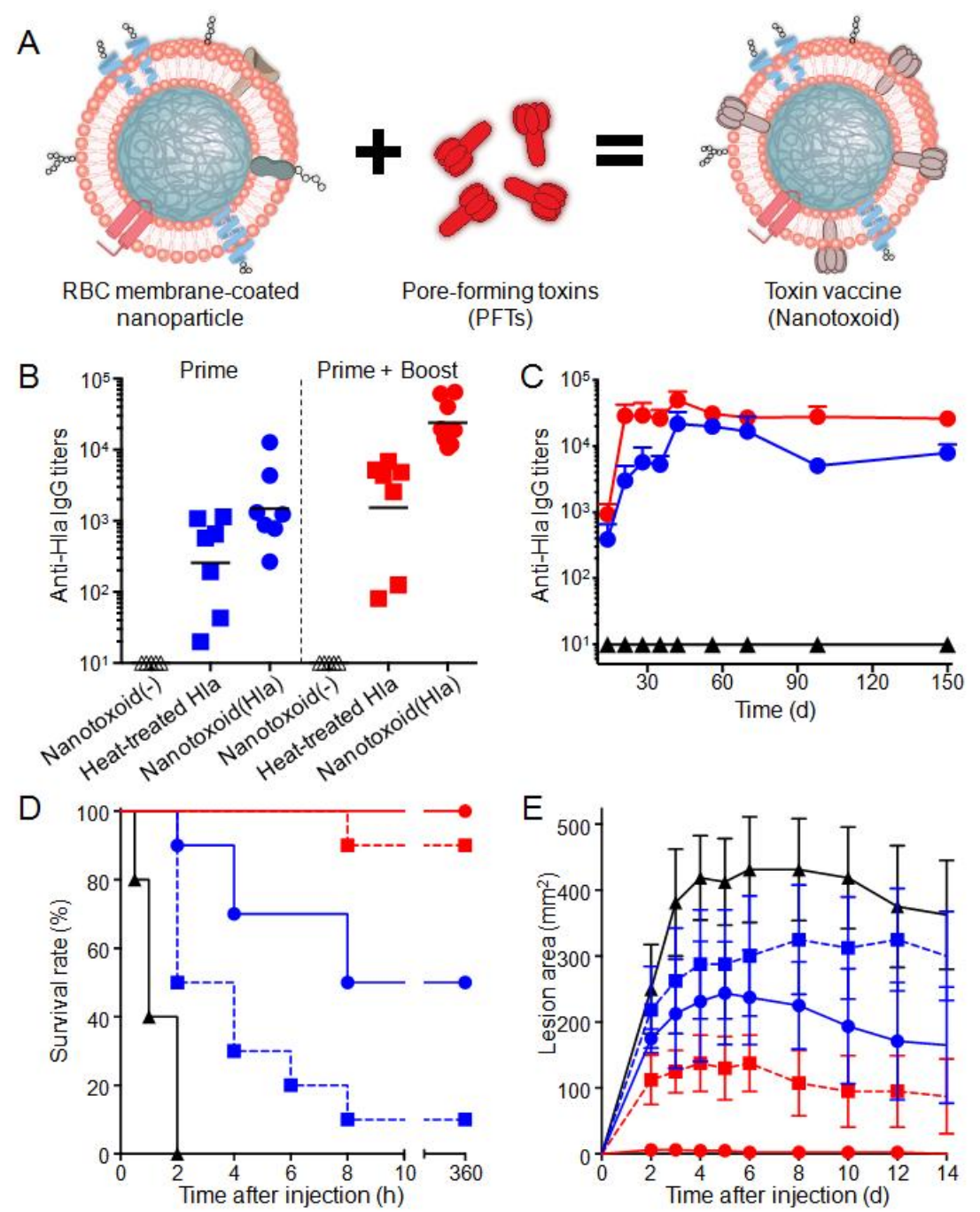

Fig. 6. Nanoparticle-detained toxins (denoted nanotoxoid) for antitoxin vaccination. (A) Schematic preparation nanotoxoid consisting of substrate-supported RBC membranes into which pore-forming toxins can incorporate. (B) Anti- $\alpha$-hemolysin (anti-Hla) IgG titers 21 days after immunization with either a prime only or prime + boost schedule. Nanotoxoid(Hla) formulations produced higher anti-Hla titer response than heat-treated Hla. (C) Time course of anti-Hla titers in unvaccinated mice (black triangles) and mice immunized with nanotoxoid(Hla) (prime + boost; red circles) or nanotoxoid(Hla) (prime only; blue circles). (D) Survival rates of mice over 15 days following intravenous injection of a lethal dose of Hla. Unvaccinated mice (black triangles) and mice vaccinated with heat-treated Hla (prime; blue squares), nanotoxoid(Hla) (prime; blue circles), heat-treated Hla (prime + boost; red squares) or nanotoxoid(Hla) (prime + boost; red circle). (E) Skin lesion size over 14 days in mice subcutaneously injected with $5 \mu \mathrm{g}$ Hla 21 days after vaccination. Reprinted with permission from [155]. 


\section{References}

[1] D.R. Nelsen, Z. Nisani, A.M. Cooper, G.A. Fox, E.C.K. Gren, A.G. Corbit, W.K. Hayes, Poisons, toxungens, and venoms: Redefining and classifying toxic biological secretions and the organisms that employ them, Biol. Rev., 89 (2014) 450-465.

[2] J.S. Henkel, M.R. Baldwin, J.T. Barbieri, Toxins from bacteria, Experientia Suppl., 100 (2010) 1-29.

[3] B.G. Fry, K. Roelants, D.E. Champagne, H. Scheib, J.D.A. Tyndall, G.F. King, T.J. Nevalainen, J.A. Norman, R.J. Lewis, R.S. Norton, C. Renjifo, R.C.R. de la Vega, The toxicogenomic multiverse: Convergent recruitment of proteins into animal venoms, Annu. Rev. Genom. Hum. G., 10 (2009) 483-511.

[4] D.H. Howard, R.D. Scott, R. Packard, D. Jones, The global impact of drug resistance, Clin. Infect. Dis., 36 (2003) S4-S10.

[5] J. White, Bites and stings from venomous animals: A global overview, Ther. Drug Monit., 22 (2000) 65-68.

[6] T.V. Inglesby, D.A. Henderson, J.G. Bartlett, M.S. Ascher, E. Eitzen, A.M. Friedlander, J. Hauer, J. McDade, M.T. Osterholm, T. O'Toole, G. Parker, T.M. Perl, P.K. Russell, K. Tonat, W.G.C. Biodefense, Anthrax as a biological weapon - Medical and public health management, Jama-J. Am. Med. Assoc., 281 (1999) 1735-1745.

[7] D.A. Rasko, V. Sperandio, Anti-virulence strategies to combat bacteria-mediated disease, Nat. Rev. Drug Discov., 9 (2010) 117-128.

[8] L. Cegelski, G.R. Marshall, G.R. Eldridge, S.J. Hultgren, The biology and future prospects of antivirulence therapies, Nat. Rev. Microbiol., 6 (2008) 17-27.

[9] R.L. Guerrant, T.S. Steiner, A.A.M. Lima, D.A. Bobak, How intestinal bacteria cause disease, J. Infect. Dis., 179 (1999) S331-S337.

[10] B. Mellbye, M. Schuster, The sociomicrobiology of antivirulence drug resistance: A proof of concept, MBio, 2 (2011) e00131-11.

[11] H. Nikaido, Multidrug resistance in bacteria, Annu. Rev. Biochem., 78 (2009) 119-146.

[12] J. Davies, D. Davies, Origins and evolution of antibiotic resistance, Microbiol. Mol. Biol. Rev., 74 (2010) 417-433. 
[13] G.J.A. Rainey, J.A.T. Young, Antitoxins: Novel strategies to target agents of bioterrorism, Nat. Rev. Microbiol., 2 (2004) 721-726.

[14] G. Hussack, J. Tanha, Toxin-specific antibodies for the treatment of clostridium difficile: Current status and future perspectives, Toxins, 2 (2010) 998-1018.

[15] A.A. Vassilevski, S.A. Kozlov, E.V. Grishin, Molecular diversity of spider venom, Biochemistry-Moscow+, 74 (2009) 1505-1534.

[16] R.A. de Maagd, A. Bravo, C. Berry, N. Crickmore, H.E. Schnepf, Structure, diversity, and evolution of protein toxins from spore-forming entomopathogenic bacteria, Annu. Rev. Genet., 37 (2003) 409-433.

[17] C.M.J. Hu, R.H. Fang, J. Copp, B.T. Luk, L.F. Zhang, A biomimetic nanosponge that absorbs pore-forming toxins, Nat. Nanotechnol., 8 (2013) 336-340.

[18] B.D. Henry, D.R. Neill, K.A. Becker, S. Gore, L. Bricio-Moreno, R. Ziobro, M.J. Edwards, K. Muhlemann, J. Steinmann, B. Kleuser, L. Japtok, M. Luginbuhl, H. Wolfmeier, A. Scherag, E. Gulbins, A. Kadioglu, A. Draeger, E.B. Babiychuk, Engineered liposomes sequester bacterial exotoxins and protect from severe invasive infections in mice, Nat. Biotechnol., 33 (2014) 81-88.

[19] B. Geny, M.R. Popoff, Bacterial protein toxins and lipids: Pore formation or toxin entry into cells, Biol. Cell, 98 (2006) 667-678.

[20] N. Reig, F.G. van der Goot, About lipids and toxins, FEBS Lett., 580 (2006) 5572-5579.

[21] P.H. Fishman, Role of membrane gangliosides in the binding and action of bacterial toxins, J. Membrane Biol., 69 (1982) 85-97.

[22] L. Eidels, R.L. Proia, D.A. Hart, Membrane-receptors for bacterial toxins, Microbiol. Rev., 47 (1983) 596-620.

[23] R.J. Youle, G.J. Murray, D.M. Neville, Ricin linked to monophosphopentamannose binds to fibroblast lysosomal hydrolase receptors, resulting in a cell-type-specific toxin, Proc. Natl. Acad. Sci. USA, 76 (1979) 5559-5562.

[24] E.W. Mccleskey, A.P. Fox, D.H. Feldman, L.J. Cruz, B.M. Olivera, R.W. Tsien, D. Yoshikami, Omega-conotoxin - Direct and persistent blockade of specific types of calcium channels in neurons but not muscle, Proc. Natl. Acad. Sci. USA, 84 (1987) 4327-4331. 
[25] G.A. Wilke, J.B. Wardenburg, Role of a disintegrin and metalloprotease 10 in Staphylococcus aureus alpha-hemolysin-mediated cellular injury, Proc. Natl. Acad. Sci. USA, 107 (2010) 13473-13478.

[26] S. Mouhat, N. Andreotti, B. Jouirou, J.M. Sabatier, Animal toxins acting on voltage-gated potassium channels, Curr. Pharm. Design, 14 (2008) 2503-2518.

[27] S. Cowell, W. Aschauer, H.J. Gruber, K.L. Nelson, J.T. Buckley, The erythrocyte receptor for the channel-forming toxin aerolysin is a novel glycosylphosphatidylinositol-anchored protein, Mol. Microbiol., 25 (1997) 343-350.

[28] L. Abrami, F.G. van der Goot, Plasma membrane microdomains act as concentration platforms to facilitate intoxication by aerolysin, J. Cell Biol., 147 (1999) 175-184.

[29] J.A.T. Young, R.J. Collier, Anthrax toxin: Receptor binding, internalization, pore formation, and translocation, Annu. Rev. Biochem., 76 (2007) 243-265.

[30] E. Valentin, G. Lambeau, What can venom phospholipases A(2) tell us about the functional diversity of mammalian secreted phospholipases A(2)?, Biochimie, 82 (2000) 815-831.

[31] J. Holmgren, I. Lonnroth, J.E. Mansson, L. Svennerholm, Interaction of cholera toxin and membrane Gm1 ganglioside of small-intestine, Proc. Natl. Acad. Sci. USA, 72 (1975) 2520-2524.

[32] T.B. Helting, O. Zwisler, Structure of tetanus toxin .1. Breakdown of toxin molecule and discrimination between polypeptide fragments, J. Biol. Chem., 252 (1977) 187-193.

[33] A.M. Svennerholm, J. Holmgren, Identification of Escherichia-coli heat-labile enterotoxin by means of a ganglioside immunosorbent assay (Gm1-Elisa) procedure, Curr. Microbiol., 1 (1978) 19-23.

[34] C.A. Lingwood, H. Law, S. Richardson, M. Petric, J.L. Brunton, S. Degrandis, M. Karmali, Glycolipid binding of purified and recombinant Escherichia-coli produced verotoxin invitro, J. Biol. Chem., 262 (1987) 8834-8839.

[35] T.G. Obrig, C.B. Louise, C.A. Lingwood, B. Boyd, L. Barleymaloney, T.O. Daniel, Endothelial heterogeneity in Shiga toxin receptors and responses, J. Biol. Chem., 268 (1993) 15484-15488.

[36] H. Ewers, A. Helenius, Lipid-mediated endocytosis, CSH Perspect. Biol., 3 (2011) a004721. 
[37] A. Yamaji, Y. Sekizawa, K. Emoto, H. Sakuraba, K. Inoue, H. Kobayashi, M. Umeda, Lysenin, a novel sphingomyelin-specific binding protein, J. Biol. Chem., 273 (1998) 53005306.

[38] A. Yamaji-Hasegawa, A. Makino, T. Baba, Y. Senoh, H. Kimura-Suda, S.B. Sato, N. Terada, S. Ohno, E. Kiyokawa, M. Umeda, T. Kobayashi, Oligomerization and pore formation of a sphingomyelin-specific toxin, lysenin, J. Biol. Chem., 278 (2003) 2276222770.

[39] P. Garcia, R. Gupta, S. Shah, A.J. Morris, S.A. Rudge, S. Scarlata, V. Petrova, S. McLaughlin, M.J. Rebecchi, The pleckstrin homology domain of phospholipase C-delta(1) binds with high affinity to phosphatidylinositol 4,5-bisphosphate in bilayer membranes, Biochemistry-US, 34 (1995) 16228-16234.

[40] M. Mosior, D.A. Six, E.A. Dennis, Group IV cytosolic phospholipase A(2) binds with high affinity and specificity to phosphatidylinositol 4,5-bisphosphate resulting in dramatic increases in activity, J. Biol. Chem., 273 (1998) 2184-2191.

[41] D.H. Schmiel, V.L. Miller, Bacterial phospholipases and pathogenesis, Microbes Infect., 1 (1999) 1103-1112.

[42] R.A. Shipolin, G.L. Callewae, R.C. Cottrell, S. Doonan, C.A. Vernon, B.E.C. Banks, Phospholipase-a from bee venom, Eur. J. Biochem., 20 (1971) 459-468.

[43] E.A. Dennis, P.L. Darke, R.A. Deems, C.R. Kensil, A. Pluckthun, Cobra Venom Phospholipase-A2 - a review of its action toward lipid-water interfaces, Mol. Cell. Biochem., 36 (1981) 37-45.

[44] M. Palmer, Cholesterol and the activity of bacterial toxins, FEMS Microbiol. Lett., 238 (2004) 281-289.

[45] R.K. Tweten, Cholesterol-dependent cytolysins, a family of versatile pore-forming toxins, Infect. Immun., 73 (2005) 6199-6209.

[46] Y. Ohno-Iwashita, Y. Shimada, A.A. Waheed, M. Hayashi, M. Inomata, M. Nakamura, M. Maruya, S. Iwashita, Perfringolysin O, a cholesterol-binding cytolysin, as a probe for lipid rafts, Anaerobe, 10 (2004) 125-134.

[47] A.J. Farrand, S. LaChapelle, E.M. Hotze, A.E. Johnson, R.K. Tweten, Only two amino acids are essential for cytolytic toxin recognition of cholesterol at the membrane surface, Proc. Natl. Acad. Sci. USA, 107 (2010) 4341-4346. 
[48] J.R. Harris, M. Palmer, Cholesterol specificity of some heptameric beta-barrel poreforming bacterial toxins: Structural and functional aspects, Subcell. Biochem., 51 (2010) 579-596.

[49] S. Miyata, J. Minami, E. Tamai, O. Matsushita, S. Shimamoto, A. Okabe, Clostridium perfringens epsilon-toxin forms a heptameric pore within the detergent-insoluble microdomains of Madin-Darby canine kidney cells and rat synaptosomes, J. Biol. Chem., 277 (2002) 39463-39468.

[50] H.M. Verheij, M.C. Boffa, C. Rothen, M.C. Bryckaert, R. Verger, G.H. Dehaas, Correlation of enzymatic-activity and anti-coagulant properties of phospholipase-A2, Eur. J. Biochem., 112 (1980) 25-32.

[51] C. Diaz, G. Leon, A. Rucavado, N. Rojas, A.J. Schroit, J.M. Gutierrez, Modulation of the susceptibility of human erythrocytes to snake venom myotoxic phospholipases $A(2)$ : Role of negatively charged phospholipids as potential membrane binding sites, Arch. Biochem. Biophys., 391 (2001) 56-64.

[52] D.L. Scott, A.M. Mandel, P.B. Sigler, B. Honig, The electrostatic basis for the interfacial binding of secretary phospholipases a(2), Biophys. J., 67 (1994) 493-504.

[53] X.Q. Huang, F. Dong, H.X. Zhou, Electrostatic recognition and induced fit in the k-PVIIA toxin binding to Shaker potassium channel, J. Am. Chem. Soc., 127 (2005) 6836-6849.

[54] K. Hall, T.H. Lee, M.I. Aguilar, The role of electrostatic interactions in the membrane binding of melittin, J. Mol. Recognit., 24 (2011) 108-118.

[55] M.R. Gonzalez, M. Bischofberger, L. Pernot, F.G. van der Goot, B. Freche, Bacterial poreforming toxins: The (w)hole story?, Cell. Mol. Life Sci., 65 (2008) 493-507.

[56] E. Gouaux, alpha-hemolysin from Staphylococcus aureus: An archetype of beta-barrel, channel-forming toxins, J. Struct. Biol., 121 (1998) 110-122.

[57] M.W. Parker, F.G. vanderGoot, J.T. Buckley, Aerolysin - The ins and outs of a model channel-forming toxin, Mol. Microbiol., 19 (1996) 205-212.

[58] S. Pantano, C. Montecucco, A molecular model of the Vibrio cholerae cytolysin transmembrane pore, Toxicon, 47 (2006) 35-40.

[59] S.J. Tilley, H.R. Saibil, The mechanism of pore formation by bacterial toxins, Curr. Opin. Struc. Biol., 16 (2006) 230-236. 
[60] L. Abrami, M. Fivaz, E. Decroly, N.G. Seidah, F. Jean, G. Thomas, S.H. Leppla, J.T. Buckley, F.G. van der Goot, The pore-forming toxin proaerolysin is activated by furin, J. Biol. Chem., 273 (1998) 32656-32661.

[61] V.T. Nguyen, Y. Kamio, Cooperative assembly of beta-barrel pore-forming toxins, J. Biochem., 136 (2004) 563-567.

[62] F. Forouhar, W.N. Huang, J.H. Liu, K.Y. Chien, W.G. Wu, C.D. Hsiao, Structural basis of membrane-induced cardiotoxin A3 oligomerization, J. Biol. Chem., 278 (2003) 2198021988.

[63] M.T. Lee, T.L. Sun, W.C. Hung, H.W. Huang, Process of inducing pores in membranes by melittin, Proc. Natl. Acad. Sci. USA, 110 (2013) 14243-14248.

[64] R.G. Thomas, F.H. Pough, Effect of rattlesnake venom on digestion of prey, Toxicon, 17 (1979) 221-228.

[65] D.K. O'Brien, S.B. Melville, Effects of Clostridium perfringens alpha-toxin (PLC) and perfringolysin $\mathrm{O}(\mathrm{PFO})$ on cytotoxicity to macrophages, on escape from the phagosomes of macrophages, and on persistence of C-perfringens in host tissues, Infect. Immun., 72 (2004) 5204-5215.

[66] A.E. Berstad, K. Berstad, A. Berstad, pH-activated phospholipase A(2): An important mucosal barrier breaker in peptic ulcer disease, Scand. J. Gastroentero., 37 (2002) 738-742.

[67] M.A. Ghannoum, Potential role of phospholipases in virulence and fungal pathogenesis, Clin. Microbiol. Rev., 13 (2000) 122-143.

[68] T. Proft, J.D. Fraser, Bacterial superantigens, Clin. Exp. Immunol., 133 (2003) 299-306.

[69] S.R. Webb, N.R.J. Gascoigne, T-cell activation by superantigens, Curr. Opin. Immunol., 6 (1994) 467-475.

[70] A.R. Spaulding, W. Salgado-Pabon, P.L. Kohler, A.R. Horswill, D.Y.M. Leung, P.M. Schlievert, Staphylococcal and streptococcal superantigen exotoxins, Clin. Microbiol. Rev., 26 (2013) 422-447.

[71] M. Field, L.H. Graf, W.J. Laird, P.L. Smith, Heat-stable enterotoxin of Escherichia-coli Invitro effects on guanylate cyclase activity, cyclic-Gmp concentration, and ion-transport in small-intestine, Proc. Natl. Acad. Sci. USA, 75 (1978) 2800-2804.

[72] S. Nirthanan, M.C.E. Gwee, Three-finger alpha-neurotoxins and the nicotinic acetylcholine receptor, forty years on, J. Pharmacol. Sci., 94 (2004) 1-17. 
[73] C.M. Barber, G.K. Isbister, W.C. Hodgson, Alpha neurotoxins, Toxicon, 66 (2013) 47-58.

[74] E. Karlsson, P.M. Mbugua, D. Rodriguezithurralde, Fasciculins, anticholinesterase toxins from the venom of the green mamba Dendroaspis-angusticeps, J. Physiol. Paris, 79 (1984) 232-240.

[75] M. Stevens, S. Peigneur, J. Tytgat, Neurotoxins and their binding areas on voltage-gated sodium channels, Front. Pharmacol., 2 (2011) 71.

[76] S.R. Sousa, I. Vetter, R.J. Lewis, Venom peptides as a rich source of $\mathrm{Ca}(\mathrm{v}) 2.2$ channel blockers, Toxins, 5 (2013) 286-314.

[77] I. Restrepo-Angulo, A. De Vizcaya-Ruiz, J. Camacho, Ion channels in toxicology, J. Appl. Toxicol, 30 (2010) 497-512.

[78] J.A. Debin, J.E. Maggio, G.R. Strichartz, Purification and characterization of chlorotoxin, a chloride channel ligand from the venom of the scorpion, Am. J. Physiol., 264 (1993) C361C369.

[79] A.L. Harvey, E. Karlsson, Dendrotoxin from the venom of the green mamba, Dendroaspisangusticeps - a neurotoxin that enhances acetylcholine-release at neuromuscular-junctions, N-S Arch. Pharmacol., 312 (1980) 1-6.

[80] R. Chau, J.A. Kalaitzis, B.A. Neilan, On the origins and biosynthesis of tetrodotoxin, Aquat. Toxicol., 104 (2011) 61-72.

[81] Y.A. Ovchinnikov, E.V. Grishin, Scorpion neurotoxins as tools for studying fast sodiumchannels, Trends Biochem. Sci., 7 (1982) 26-28.

[82] R. Veneziano, C. Rossi, A. Chenal, J.M. Devoisselle, D. Ladant, J. Chopineau, Bordetella pertussis adenylate cyclase toxin translocation across a tethered lipid bilayer, Proc. Natl. Acad. Sci. USA, 110 (2013) 20473-20478.

[83] H. Barth, K. Aktories, M.R. Popoff, B.G. Stiles, Binary bacterial toxins: Biochemistry, biology, and applications of common Clostridium and Bacillus proteins, Microbiol. Mol. Biol. Rev., 68 (2004) 373-402.

[84] J.R. Murphy, Mechanism of diphtheria toxin catalytic domain delivery to the eukaryotic cell cytosol and the cellular factors that directly participate in the process, Toxins, 3 (2011) 294-308.

[85] R.A. Spooner, D.C. Smith, A.J. Easton, L.M. Roberts, J.M. Lord, Retrograde transport pathways utilised by viruses and protein toxins, Virol. J., 3 (2006). 
[86] L. Johannes, W. Romer, Shiga toxins - from cell biology to biomedical applications, Nat. Rev. Microbiol., 8 (2010) 105-116.

[87] J.M. Lord, L.M. Roberts, J.D. Robertus, Ricin: structure, mode of action, and some current applications, FASEB J., 8 (1994) 201-208.

[88] W.I. Lencer, T.R. Hirst, R.K. Holmes, Membrane traffic and the cellular uptake of cholera toxin, Biochim. Biophys. Acta, 1450 (1999) 177-190.

[89] R.A. Spooner, J.M. Lord, How ricin and Shiga toxin reach the cytosol of target cells: Retrotranslocation from the endoplasmic reticulum, Curr .Top. Microbiol., 357 (2012) 1940 .

[90] A.K.J. Veenendaal, J.L. Hodgkinson, L. Schwarzer, D. Stabat, S.F. Zenk, A.J. Blocker, The type III secretion system needle tip complex mediates host cell sensing and translocon insertion, Mol. Microbiol., 63 (2007) 1719-1730.

[91] R.D. Hayward, R.J. Cain, E.J. McGhie, N. Phillips, M.J. Garner, V. Koronakis, Cholesterol binding by the bacterial type III translocon is essential for virulence effector delivery into mammalian cells, Mol. Microbiol., 56 (2005) 590-603.

[92] D.K. Shen, S. Saurya, C. Wagner, H. Nishioka, A.J. Blocker, Domains of the Shigella flexneri type III secretion system IpaB protein involved in secretion regulation, Infect. Immun., 78 (2010) 4999-5010.

[93] B. Coburn, I. Sekirov, B.B. Finlay, Type III secretion systems and disease, Clin. Microbiol. Rev, 20 (2007) 535-549.

[94] A.D. Bangham, M.M. Standish, G. Weissmann, The action of steroids and streptolysin S on the permeability of phospholipid structures to cations, J. Mol. Biol., 13 (1965) 253-259.

[95] G. Weissmann, G. Sessa, A.W. Bernheimer, Staphylococcal alpha-toxin: effects on artificial lipid spherules, Science, 154 (1966) 772-774.

[96] J.L. Duncan, R. Schlegel, Effect of streptolysin O on erythrocyte membranes, liposomes, and lipid dispersions. A protein-cholesterol interaction, J. Cell Biol., 67 (1975) 160-174.

[97] C.R. Alving, B.H. Iglewski, K.A. Urban, J. Moss, R.L. Richards, J.C. Sadoff, Binding of diphtheria toxin to phospholipids in liposomes, Proc. Natl. Acad. Sci. USA, 77 (1980) 1986-1990.

[98] B.L. Kagan, A. Finkelstein, M. Colombini, Diphtheria toxin fragment forms large pores in phospholipid bilayer membranes, Proc. Natl. Acad. Sci. USA, 78 (1981) 4950-4954. 
[99] A. Alonso, F.M. Goni, J.T. Buckley, Lipids favoring inverted phase enhance the ability of aerolysin to permeabilize liposome bilayers, Biochemistry, 39 (2000) 14019-14024.

[100] S.J. Tilley, E.V. Orlova, R.J. Gilbert, P.W. Andrew, H.R. Saibil, Structural basis of pore formation by the bacterial toxin pneumolysin, Cell, 121 (2005) 247-256.

[101] J.L. Cowell, A.W. Bernheimer, Role of cholesterol in the action of cereolysin on membranes, Arch. Biochem. Biophys., 190 (1978) 603-610.

[102] C.R. Alving, W.H. Habig, K.A. Urban, M.C. Hardegree, Cholesterol-dependent tetanolysin damage to liposomes, Biochim. Biophys. Acta, 551 (1979) 224-228.

[103] P. Bougis, H. Rochat, G. Pieroni, R. Verger, Penetration of phospholipid monolayers by cardiotoxins, Biochemistry, 20 (1981) 4915-4920.

[104] G. Sessa, J.H. Freer, G. Colacicco, G. Weissmann, Interaction of alytic polypeptide, melittin, with lipid membrane systems, J. Biol. Chem., 244 (1969) 3575-3582.

[105] M. Nagahama, K. Michiue, J. Sakurai, Membrane-damaging action of Clostridium perfringens alpha-toxin on phospholipid liposomes, Biochim. Biophys. Acta, 1280 (1996) 120-126.

[106] H. Shogomori, T. Kobayashi, Lysenin: A sphingomyelin specific pore-forming toxin, Biochim. Biophys. Acta, 1780 (2008) 612-618.

[107] A.K. Singh, S.H. Harrison, J.S. Schoeniger, Gangliosides as receptors for biological toxins: Development of sensitive fluoroimmunoassays using ganglioside-bearing liposomes, Anal. Chem., 72 (2000) 6019-6024.

[108] J.J. Pan, D. Charych, Molecular recognition and colorimetric detection of cholera toxin by poly(diacetylene) liposomes incorporating G(m1) ganglioside, Langmuir, 13 (1997) 13651367.

[109] L. Alfonta, I. Willner, D.J. Throckmorton, A.K. Singh, Electrochemical and quartz crystal microbalance detection of the cholera toxin employing horseradish peroxidase and GM1functionalized liposomes, Anal. Chem., 73 (2001) 5287-5295.

[110] S. Ahn-Yoon, T.R. DeCory, A.J. Baeumner, R.A. Durst, Ganglioside-liposome immunoassay for the ultrasensitive detection of cholera toxin, Anal. Chem., 75 (2003) 2256-2261.

[111] D. Pornpattananangkul, L. Zhang, S. Olson, S. Aryal, M. Obonyo, K. Vecchio, C.M. Huang, L.F. Zhang, Bacterial toxin-triggered drug release from gold nanoparticle-stabilized 
liposomes for the treatment of bacterial infection, J. Am. Chem. Soc., 133 (2011) 41324139.

[112] I. Cheong, X. Huang, C. Bettegowda, L.A. Diaz, Jr., K.W. Kinzler, S. Zhou, B. Vogelstein, A bacterial protein enhances the release and efficacy of liposomal cancer drugs, Science, 314 (2006) 1308-1311.

[113] S. Thamphiwatana, W.W. Gao, D. Pornpattananangkul, Q.Z. Zhang, V. Fu, J.Y. Li, J.M. Li, M. Obonyo, L.F. Zhang, Phospholipase A2-responsive antibiotic delivery via nanoparticle-stabilized liposomes for the treatment of bacterial infection, J. Mater. Chem. B, 2 (2014) 8201-8207.

[114] B.S. Zolnik, A. Gonzalez-Fernandez, N. Sadrieh, M.A. Dobrovolskaia, Nanoparticles and the immune system, Endocrinology, 151 (2010) 458-465.

[115] S. Basha, P. Rai, V. Poon, A. Saraph, K. Gujraty, M.Y. Go, S. Sadacharan, M. Frost, J. Mogridge, R.S. Kane, Polyvalent inhibitors of anthrax toxin that target host receptors, Proc. Natl. Acad. Sci. USA, 103 (2006) 13509-13513.

[116] D. Lingwood, K. Simons, Lipid rafts as a membrane-organizing principle, Science, 327 (2010) 46-50.

[117] C.L. Malmendier, C. Delcroix, J.P. Ameryckx, In vivo metabolism of human apoprotein A-I-phospholipid complexes. Comparison with human high density lipoprotein-apoprotein A-I metabolism, Clin. Chim. Acta, 131 (1983) 201-210.

[118] M.R. Whorton, M.P. Bokoch, S.G. Rasmussen, B. Huang, R.N. Zare, B. Kobilka, R.K. Sunahara, A monomeric G protein-coupled receptor isolated in a high-density lipoprotein particle efficiently activates its G protein, Proc. Natl. Acad. Sci USA, 104 (2007) 76827687.

[119] D.A. Bricarello, J.T. Smilowitz, A.M. Zivkovic, J.B. German, A.N. Parikh, Reconstituted lipoprotein: A versatile class of biologically-inspired nanostructures, ACS Nano, 5 (2011) 42-57.

[120] T.H. Bayburt, A.J. Leitz, G. Xie, D.D. Oprian, S.G. Sligar, Transducin activation by nanoscale lipid bilayers containing one and two rhodopsins, J. Biol. Chem., 282 (2007) 14875-14881.

[121] J.A. Cappuccio, A.K. Hinz, E.A. Kuhn, J.E. Fletcher, E.S. Arroyo, P.T. Henderson, C.D. Blanchette, V.L. Walsworth, M.H. Corzett, R.J. Law, J.B. Pesavento, B.W. Segelke, T.A. 
Sulchek, B.A. Chromy, F. Katzen, T. Peterson, G. Bench, W. Kudlicki, P.D. Hoeprich, Jr., M.A. Coleman, Cell-free expression for nanolipoprotein particles: Building a highthroughput membrane protein solubility platform, Methods Mol. Biol., 498 (2009) 273296.

[122] S.E. Baker, R.C. Hopkins, C.D. Blanchette, V.L. Walsworth, R. Sumbad, N.O. Fischer, E.A. Kuhn, M. Coleman, B.A. Chromy, S.E. Letant, P.D. Hoeprich, M.W. Adams, P.T. Henderson, Hydrogen production by a hyperthermophilic membrane-bound hydrogenase in water-soluble nanolipoprotein particles, J. Am. Chem. Soc., 131 (2009) 7508-7509.

[123] T.H. Bayburt, S.G. Sligar, Self-assembly of single integral membrane proteins into soluble nanoscale phospholipid bilayers, Protein Sci, 12 (2003) 2476-2481.

[124] L. Seganti, P. Valenti, P. Mastromarino, L. Sinibaldi, A. De Stasio, N. Orsi, Inhibition of staphylococcal beta-hemolysin by human serum lipoproteins and their components, Ann. Sclavo, 22 (1980) 719-728.

[125] J. Badin, A. Barillec, Streptolysin O inhibition by serum gamma G-globulin and betalipoprotein after blocking of nonesterified cholesterol by digitonin, J. Lab. Clin. Med., 75 (1970) 975-982.

[126] Y. Fukuchi, Y. Kudo, T. Kumagai, K. Ebina, K. Yokota, Oxidized low density lipoprotein inhibits the hemolytic activity of Asp-hemolysin from Aspergillus fumigatus, FEMS Microbiol. Lett., 167 (1998) 275-280.

[127] A.W. Bernheimer, L.S. Avigad, Properties of a toxin from the sea anemone Stoichacis helianthus, including specific binding to sphingomyelin, Proc. Natl. Acad. Sci. USA, 73 (1976) 467-471.

[128] D.A. Bricarello, E.J. Mills, J. Petrlova, J.C. Voss, A.N. Parikh, Ganglioside embedded in reconstituted lipoprotein binds cholera toxin with elevated affinity, J. Lipid Res., 51 (2010) 2731-2738.

[129] S. Lauer, B. Goldstein, R.L. Nolan, J.P. Nolan, Analysis of cholera toxin-ganglioside interactions by flow cytometry, Biochemistry, 41 (2002) 1742-1751.

[130] J.R. Sheng, S. Grimme, P. Bhattacharya, M.H. Stowell, M. Artinger, B.S. Prabahakar, M.N. Meriggioli, In vivo adsorption of autoantibodies in myasthenia gravis using Nanodisc-incorporated acetylcholine receptor, Exp. Neurol., 225 (2010) 320-327. 
[131] D.A. Bricarello, M.A. Patel, A.N. Parikh, Inhibiting host-pathogen interactions using membrane-based nanostructures, Trends Biotechnol., 30 (2012) 323-330.

[132] J. Aizenberg, P. Fratzl, Biological and biomimetic materials, Adv. Mater., 21 (2009) 387388.

[133] C. Thery, M. Ostrowski, E. Segura, Membrane vesicles as conveyors of immune responses, Nat. Rev. Immunol., 9 (2009) 581-593.

[134] S.R. Denmeade, A.M. Mhaka, D.M. Rosen, W.N. Brennen, S. Dalrymple, I. Dach, C. Olesen, B. Gurel, A.M. Demarzo, G. Wilding, M.A. Carducci, C.A. Dionne, J.V. Moller, P. Nissen, S.B. Christensen, J.T. Isaacs, Engineering a prostate-specific membrane antigenactivated tumor endothelial cell prodrug for cancer therapy, Sci. Transl. Med., 4 (2012) 140ra186.

[135] M.T. Stephan, D.J. Irvine, Enhancing cell therapies from the outside in: Cell surface engineering using synthetic nanomaterials, Nano Today, 6 (2011) 309-325.

[136] J.V. de Carvalho, R.O. de Castro, E.Z. da Silva, P.P. Silveira, M.E. da Silva-Januario, E. Arruda, M.C. Jamur, C. Oliver, R.S. Aguiar, L.L. daSilva, Nef neutralizes the ability of exosomes from CD4+ T cells to act as decoys during HIV-1 infection, PloS One, 9 (2014) e113691.

[137] J.M. Inal, E.A. Ansa-Addo, S. Lange, Interplay of host-pathogen microvesicles and their role in infectious disease, Biochem. Soc. Trans., 41 (2013) 258-262.

[138] S. Bhakdi, J. Tranumjensen, Damage to mammalian-cells by proteins that form transmembrane pores, Rev. Physiol. Bioch. Pharmacol., 107 (1987) 147-223.

[139] T.L. Steck, The organization of proteins in the human red blood cell membrane. A review, J. Cell Biol., 62 (1974) 1-19.

[140] A. Lejeune, M. Moorjani, C. Gicquaud, J. Lacroix, P. Poyet, R. Gaudreault, Nanoerythrosome, a new derivative of erythrocyte ghost: Preparation and antineoplastic potential as drug carrier for daunorubicin, Anticancer Res., 14 (1994) 915-919.

[141] C.M. Hu, L. Zhang, S. Aryal, C. Cheung, R.H. Fang, L. Zhang, Erythrocyte membranecamouflaged polymeric nanoparticles as a biomimetic delivery platform, Proc. Natl. Acad. Sci. USA, 108 (2011) 10980-10985. 
[142] C.M. Hu, R.H. Fang, B.T. Luk, K.N. Chen, C. Carpenter, W. Gao, K. Zhang, L. Zhang, 'Marker-of-self' functionalization of nanoscale particles through a top-down cellular membrane coating approach, Nanoscale, 5 (2013) 2664-2668.

[143] B.T. Luk, C.M. Hu, R.H. Fang, D. Dehaini, C. Carpenter, W. Gao, L. Zhang, Interfacial interactions between natural RBC membranes and synthetic polymeric nanoparticles, Nanoscale, 6 (2014) 2730-2737.

[144] A. Parodi, N. Quattrocchi, A.L. van de Ven, C. Chiappini, M. Evangelopoulos, J.O. Martinez, B.S. Brown, S.Z. Khaled, I.K. Yazdi, M.V. Enzo, L. Isenhart, M. Ferrari, E. Tasciotti, Synthetic nanoparticles functionalized with biomimetic leukocyte membranes possess cell-like functions, Nat. Nanotechnol., 8 (2013) 61-68.

[145] R.H. Fang, C.M. Hu, B.T. Luk, W. Gao, J.A. Copp, Y. Tai, D.E. O'Connor, L. Zhang, Cancer cell membrane-coated nanoparticles for anticancer vaccination and drug delivery, Nano Lett., 14 (2014) 2181-2188.

[146] J.A. Copp, R.H. Fang, B.T. Luk, C.M.J. Hu, W.W. Gao, K. Zhang, L.F. Zhang, Clearance of pathological antibodies using biomimetic nanoparticles, Proc. Natl. Acad. Sci. USA, 111 (2014) 13481-13486.

[147] E.A. Mortimer, Jr., Immunization against infectious disease, Science, 200 (1978) 902-907.

[148] B. Metz, G.F. Kersten, P. Hoogerhout, H.F. Brugghe, H.A. Timmermans, A. de Jong, H. Meiring, J. ten Hove, W.E. Hennink, D.J. Crommelin, W. Jiskoot, Identification of formaldehyde-induced modifications in proteins: Reactions with model peptides, J. Biol. Chem., 279 (2004) 6235-6243.

[149] S.J. Cryz, Jr., E. Furer, R. Germanier, Effect of chemical and heat inactivation on the antigenicity and immunogenicity of Vibrio cholerae, Infect. Immun., 38 (1982) 21-26.

[150] R.G.A. Jones, Y. Liu, P. Rigsby, D. Sesardic, An improved method for development of toxoid vaccines and antitoxins, J. Immunol. Methods, 337 (2008) 42-48.

[151] A.D. Kennedy, J. Bubeck Wardenburg, D.J. Gardner, D. Long, A.R. Whitney, K.R. Braughton, O. Schneewind, F.R. DeLeo, Targeting of alpha-hemolysin by active or passive immunization decreases severity of USA300 skin infection in a mouse model, J. Infect. Dis., 202 (2010) 1050-1058.

[152] R.P. Adhikari, H. Karauzum, J. Sarwar, L. Abaandou, M. Mahmoudieh, A.R. Boroun, H. Vu, T. Nguyen, V.S. Devi, S. Shulenin, K.L. Warfield, M.J. Aman, Novel structurally 
designed vaccine for S. aureus alpha-hemolysin: Protection against bacteremia and pneumonia, PLoS One, 7 (2012) e38567.

[153] S.I. Jang, H.S. Lillehoj, S.H. Lee, K.W. Lee, E.P. Lillehoj, Y.H. Hong, D.J. An, W. Jeong, J.E. Chun, F. Bertrand, L. Dupuis, S. Deville, J.B. Arous, Vaccination with Clostridium perfringens recombinant proteins in combination with Montanide ISA 71 VG adjuvant increases protection against experimental necrotic enteritis in commercial broiler chickens, Vaccine, 30 (2012) 5401-5406.

[154] L.A. Kirkham, A.R. Kerr, G.R. Douce, G.K. Paterson, D.A. Dilts, D.F. Liu, T.J. Mitchell, Construction and immunological characterization of a novel nontoxic protective pneumolysin mutant for use in future pneumococcal vaccines, Infect. Immun., 74 (2006) 586-593.

[155] C.M.J. Hu, R.H. Fang, B.T. Luk, L.F. Zhang, Nanoparticle-detained toxins for safe and effective vaccination, Nat. Nanotechnol., 8 (2013) 933-938.

[156] S.G. Fonseca, A.M.M. Ferreira, C.R. Diniz, C. Chavez-Olortegui, Induction of neutralizing antibodies in mice immunized with scorpion toxins detoxified by liposomal entrapment, Braz. J. Med. Biol. Res., 30 (1997) 883-886.

[157] T.V. Freitas, C.R. Diniz, F. Frezard, The use of liposomes as snake venom vehicles: Application in protective immunization., J. Toxicol. Toxin Rev., 17 (1998) 441-466.

[158] C. Chavez-Olortegui, D.A. Amara, H. Rochat, C. Diniz, C. Granier, In vivo protection against scorpion toxins by liposomal immunization, Vaccine, 9 (1991) 907-910. 